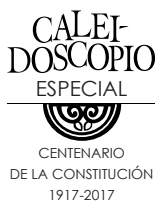

\title{
Reseña de Paxman (2016). En busca del señor Jenkins
}

Review of Paxman (2016). En busca del señor Jenkins

ANDRÉS REYES RODRÍGUEZ'

Paxman, A. (2016). En busca del señor Jenkins. Dinero, poder y gringofobia en México. Ciudad de México: Debate.

El libro de Andrew Paxman, En busca del señor Jenkins, ha sido presentado ya en varios estados de la República y también en varios foros de radio y televisión del país. ${ }^{2}$ Con este antecedente, el primer reto para traerlo a cuenta en Aguascalientes -lugar en el que reside el autor del texto- era generar una opinión distinta a la ya expresada con anterioridad. El desafío más importante para iniciar la lectura del libro consiste en la amplitud. Es un texto de 604 páginas, divididas en 11 apartados; 32 de ellas con fotografías y aproximadamente 60 de biblio-

1 areyes@correo.uaa.mx.

2 Reseña elaborada a partir de los comentarios al texto presentado en la 49 Feria del Libro de Aguascalientes. grafía, notas y un índice onomástico. Consecuentemente, el reto para el nuevo lector es atreverse a leerlo con la esperanza de que sea interesante. Por fortuna, la premisa se cumple a cabalidad. La lectura del libro es fácil, y las historias que se narran muy placenteras.

Con tales dimensiones, para ser atractivo el libro tiene que seducir desde el principio. También cumple este requisito. Esta parte se debe muy posiblemente a que se trata de una biografía, es decir, de una historia privada que aborda la vida de William Jenkins, un empresario de época en México; aunque es también una existencia que bien cabe en el género de la historia económica a la que se agregan 
con frecuencia detalles cotidianos que siempre despiertan una multiplicada curiosidad. El texto habla de un emprendedor y, por lo tanto, de negocios, de socios limpios y oscuros; de una familia sui géneris y de una indudable capacidad para invertir en tiempos de crisis; y también de las actividades de relajamiento que practicaba Jenkins cuando no atendía los negocios, esa parte que genera interés simplemente porque se refiere a uno de los hombres más ricos de México en el siglo XX.

Según Andrew Paxman, Jenkins hizo dinero a partir de la nada, lo adquirió con las industrias textil, azucarera y cinematográfica. La fortuna creció también prestando dinero. En la parte más formal, el texto demuestra que el capital financiero se incrementó aprovechando contextos favorables, otorgando préstamos convenientes, realizando compras forzadas, efectuando alianzas oportunas, aplicando la ley selectivamente, evadiendo impuestos, y teniendo amistad con presidentes de la República, gobernadores, obispos y generales. A esta historia se agregan detalles de la vida cotidiana que en este tipo de trabajos suelen pasar inadvertidos. De ese modo, el lector se puede enterar que a Jenkins le gustaba madrugar, jugar tenis con frecuencia y negar categóricamente todas las invitaciones para fumar un cigarrillo. La fama no lo perturbó nunca. Pese a ser tan conocido socialmente, jamás hablaba con la prensa.

El poder acumulado por los años lo llevó a una vida contrastante. Producía bebidas con alcohol para la mafia norteamericana y generaba riqueza explotando intensivamente a sus empleados, pero también obsequiaba recursos para construir hospitales, llevar agua a zonas pobres y apoyar excavaciones en zonas arqueológicas. Al final de sus días, terminó con una imagen que lo concibió como un barón ladrón, como un protagonista del capitalismo de cuates, y también, dicho por el general Lázaro Cárdenas, como una reliquia del pasado latifundista. En una perspectiva más general y analítica, Andrew define la vida de Jenkins como un testimonio de la relación existente entre el Estado y los empresarios, entre el Estado y el capital; entre el Estado y el dinero.

El escritor e investigador del CIDE hace honor al oficio de historiador y también de periodista, refleja, además, la tradición inglesa que hay por la biografía. Fusiona entonces tres realidades que concluyen en un libro bien documentado, metodológicamente sólido, conceptualmente perti- 
nente, y con una narrativa dotada de valor literario. Paxman cuenta historias que parecen una hermosa mentira, aunque muy pronto se cae en la cuenta de que realmente se trata de lienzos descriptivos con personas de carne y hueso, de procesos históricos nacionales y de las regiones de México.

No es posible hacer una reseña que ahorre la compra del libro. No sería negocio. Es por ello que este comentario termina con la exposición de dos razones que invitan a la lectura de este documento. Una para ver el siglo XX mexicano desde la óptica empresarial, y otra más que fascina por generar ambientes de una historia narrada con espíritu de thriller cinematográfico, es decir, con dilemas por resolver que combina pasiones humanas, lealtad, engaño, amistad, control, ambición, riesgo, poder y misterio. Un thriller que suma anécdotas notables que adquieren sentido al dejar en claro que la finalidad del investigador es saciar pero, sobre todo, comprender procesos económicos, políticos y sociales de gran densidad sociológica.

Vale ahora una reiteración. En el libro de Andrew Paxman la mirada estructural y la anecdótica se complementan para comprender. Según él, Jenkins creaba su fortuna con habilidad ejemplar y, al mismo tiempo, dejaba en claro otras lecciones que hablan de una historia privada que da paso a los aforismos, como cuando inspira la idea de que "detrás de cada rico hay siempre un hombre de confianza", una conclusión que otorga sentido al emprendimiento empresarial supeditado a momentos históricos particulares. En el texto nada es superficial, y si lo es, no impide que se convierta en camino para comprender asuntos trascendentes, como la tesis de la "gringofobia", una anécdota que se transforma en hipótesis para visualizarla como una materia prima con la que se podrían entender los hilos del nacionalismo posrevolucionario.

Paxman hace historia nacional, desde la óptica de un extranjero. Tiene el espíritu viajero de su nacionalidad, por ello, como el whis$k y$, sabe andar por todas partes. Enfrenta como escritor el mismo dilema de otros ingleses en México, como Malcolm Lowry, Graham Greene y D. H. Lawrence, autores que, según Héctor Sánchez, eran movidos por emociones inmediatas, a los que les atrae su turbulencia, el surrealismo "en que los hombres parecen hombres o demonios". En una lista más contemporánea, Paxman comparte también sentimientos y emociones que han experimentado a su manera David Brading, Hugh Thomas, Will Fowler, Linda 
Colley, Paul Garner y Alan Knigth, entre otros. En este sentido, el libro es también un buen ejemplo de psicohistoria.

Hay algo más que invita a la lectura del libro: al presentarlo y difundirlo desde Aguascalientes, ofrece una mirada refrescante para pensar y hacer historia. Ayuda a verla contemporánea y accesible, interesante y digna de ser cultivada con mayor frecuencia. El libro prueba que presente y pasado están unidos inextricablemente, y confirma la vieja fórmula de que la relación con el "otro" siempre ayuda a descubrirse a sí mismo. El nuevo Andrew, el inglés transformado en hidrochilango, piensa desde varias ópticas y, sin dejar de ser extranjero, lee al país con algo de mexicanidad, tal vez por ello, con su narrativa, enseña y propone una nueva lectura de la historia empresarial, más allá de las creencias. Entrega en suma un libro que, sin pensarlo demasiado, merece un sillón y una lámpara para honrar el misterio del tiempo y la palabra. 